\title{
Development and Stability Evaluation of Enteric Coated Diclofenac Sodium Tablets Using AquaPolish E.
}

\author{
Zaid A.N. ${ }^{\dagger}$, Fadda A.M. ${ }^{1}$, Nator S. $^{2}$ and Qaddumi A. ${ }^{2}$ \\ College of Pharmacy, An- Najah National University, Nablus Palestine \\ ${ }^{1}$ College of Pharmacy University of Cagliari Italy \\ ${ }^{2}$ Pharmacare LTD, Ramallah Palestine
}

(Received April 22, $2011 \cdot$ Revised May 23, $2011 \cdot$ Accepted July 5, 2011)

\begin{abstract}
The aim of this study was to develop a stable enteric coated diclofenac sodium (DFS) tablets using AquaPolish E without using a subcoat. DFS uncoated tablets were manufactured through the non direct compression process. AquaPolish $\mathrm{E}$ white aqueous coating dispersion was used as enteric coating material. This film forming polymer is a mixture of selected polymethacrylic/ethylacrylate copolymers. The stability of the obtained enteric coated tablets was evaluated according to ICH guidelines. No signs of disintegration or cracking was observed when they placed in $0.1 \mathrm{~N} \mathrm{HCl}$ solution (pH1.2), but they were completely disintegrated within 10 minutes when they placed in buffered solution at pH6.8. Dissolution test was also conducted by placing tablets in $0.1 \mathrm{~N} \mathrm{HCl}$ for 2 hours and then 1 hour in phosphate buffer at pH 6.8. Less than $0.9 \%$ of drug was released in the acidic phase and up to $97 \%$ in the basic medium. These findings suggest that aqueous enteric coating with AquaPolish E system is an easy and economical approach for preparing stable DFS enteric coat without the use of a subcoating layer.
\end{abstract}

Key words - Enteric coating, Subcoating, AquaPolish E, Diclofenac, dispersion.

Enteric film coating is a process that involves the deposition of a thin but uniform, film onto the surface of an oral solid dosage form (Aulton, 2007). Enteric film coating is intended to either protect acid - sensitive drugs from the $\mathrm{pH}$ of the stomach or protect the stomach from the irritant effect of some drugs such as non-steroidal anti-inflammatory drugs (NSAIDs). This phenomenon can be achieved by using polymers formulations where these polymers are soluble at $\mathrm{pH}$ values higher than 5.5. Recently, acrylic copolymers were considered as the most suitable materials in providing enteric coating formulations in terms of effectiveness and global acceptability (Porter 2006). Many of these systems are pseudo latex dispersions of polymers and aqueous solutions of alkali salts (Wheatley and Steuernagel 1997).The aqueous based coating systems are preferred when compared with the organic solvent based systems due to many reasons including pollution, flammability, toxicity concerns over environmental pollution and higher cost of the solvents. As a result they impose a risk to the operators (Baudoux et al., 1990; Durriya et al., 2008; Bushra et al., 2010). AquaPolish $\mathrm{E}$ is an optimized, one-step, pigmented, aqueous based acrylic acid copolymer. It can be used to provide enteric coating, strengthen friable cores or to

†Corresponding Author:

Tel : 0097292345113,E-mail : anzaid@najah.edu

DOI : $10.4333 /$ KPS.2011.41.4.211 decrease incompatibilities between the active ingredients and the gastric resistant film coating for oral tablets, capsules and granules. This film forming polymer is a mixture of selected polymethacrylic/ethylacrylate copolymers with a completely formulated enteric coating system. It provides significant time savings in both development and production purposes (www.biogrund.com/). Generally, a subcoating step may be used before the placement of the enteric coat film. But this step is material and time consuming and remains as an optional step. Almost all NSAIDs irritate gastric mucosa and cause ulcer. This is due to their capacity in the inhibition of prostaglandin synthesis (Derle et al., 2006). Diclofenac sodium (DFS) is one of the most commonly used NSAIDs. The most important side effects of DFS include peptic ulceration and gastric perforation (http://www.webmd.com). This alkaline salt may interact with the acidic groups that are present in the acrylic polymer of AquaPolish $\mathrm{E}$ and thus it may require a subcoating layer to minimize this effect. The aims of this study is to develop and evaluate the stability of DFS enteric coated tablets without the use of a subcoating layer.

\section{Materials and Methods}

\section{Materials}

DFS was purchased from Aarti Drug limited (Mumbai, India), sodium hydroxide and monobasic potassium phosphate 
were achieved from Merck, KgaA, (Darmstadt, Germany). Aquapolish E white coating material was provided by BioGrund $\mathrm{GmbH}$ (Germany), Propylene Glycol was bought from Dow Chemical (Midland, U.S.A.). Aluminum foil was purchased from INEOS Olefins \& Polymers (Europe) and polyvinyl chloride from Klockner pentaplast(Virginia, USA). All the other used chemicals and reagents were of analytical grade and obtained from commercial sources.

\section{Methods}

DFS uncoated tablets were prepared by Pharmacare PLC. The average weight of the final uncoated tablets was about 270 $\mathrm{mg}$. The obtained tablets were visually checked while hardness, weight variation and drug content of DFS uncoated tablets were evaluated according to the United State Pharmacopeia tests (USP 2007). The weight uniformity test was conducted using Precisa 205 ASCS electronic balance (Mumbai, India). Thickness and diameters were measured using Vernier caliper while the hardness of tablets was tested using Pharma test PTB311E instrument (Hainburg, Germany). Friability was evaluated using TA-100 Erweka friability tester (Heusenstamm, Germany). Dissolution was carried out according to the USP procedure. In this test, 6 tablets were randomly selected and weighed. Each tablet was placed in $900 \mathrm{~mL}$ phosphate buffer (pH 6.8) and maintained at $37^{\circ} \mathrm{C}$. The paddle stirring rate was set at 50 round per minute (rpm). Only after passing all the above USP tests DFS uncoated tablets were selected for coating.

\section{Enteric coating of DFS (50 $\mathbf{~ m g} /$ tablet)}

Preparation of AquaPolish E for enteric coating

AquaPolish E coating dispersion was prepared according to following procedure: exactly, $1000 \mathrm{~mL}$ of distilled water was placed into a beaker and stirred to form a vortex. $300 \mathrm{~g}$ AquaPolish E white powder and $25 \mathrm{~g}$ propylene glycol were weighed accurately and added to the center of the liquid vortex in a slow steady stream. Mixing was continued for about 25 minutes. Finally, AquaPolish E aqueous dispersion was passed through a 250 micron sieve prior to the coating process in order to eliminate the presence of any clumps. Dispersion was continuously stirred during the entire period of the coating process.

\section{Coating methodology}

Tablet coating was performed in a conventional coating pan (Erweka G.m.b.H., Frankfurt, Germany) with one spray gun. $3.5 \mathrm{Kg}$ of DFS uncoated tablets were placed into the coating pan. These tablet cores were pre-heated to about $40^{\circ} \mathrm{C}$ utilizing a dryer and high pressure air spray guns (SAGOLA copy,
Ningbo, China). Warm air was introduced into the coating pan (up to $50-55^{\circ} \mathrm{C}$ ) during the entire period of the coating process. The spray gun was filled with AquaPolish E white aqueous dispersion and operated at appropriate flow rate. The pan was set into motion and coating dispersion was sprayed on to the falling cores under a suitable air pressure (6-8 bar). The air heater was switched off and tablets were blow dried for about 25 minutes in the coating pan. The core tablets gained 10-12\% weight after the deposition of AquaPolish E dispersion. The obtained coated tablets were packaged in Aluminum-PVC foil using Klöckner Hänsel packing machine (Hannover,Germany).

\section{Evaluation of DFS (50 mg) coated tablets}

Mechanical strength

The hardness of the coated tablets was examined according to the USP specification (USP 2007). 20 randomly selected tablets from each of three study batches were tested at different time intervals of the study.

\section{Disintegration test of enteric coated tablets}

The disintegration time of enteric coated DFS $50 \mathrm{mg}$ tablets was determined according to the procedure reported in the USP (USP 2007) using Erweka ZT-221disintegrator (Husenstamn, Germany).

\section{Assay for enteric coated tablets}

The amount of DFS in each tablet was determined according to the USP assay method (USP 2007). The HPLC system, Merck Hitachi, (Interface module D-7000, Autosampler L7200, Pump L-7100, Detector L-7450) was used for the analysis and quantification of DFS in the samples study. Separation was accomplished using a $250 \mathrm{~mm} \times 4.6 \mathrm{~mm}, 5.0 \mu \mathrm{m}$ Hypersil $^{\circledR}$ BDS C18 column (Table I).

\section{Dissolution test of enteric coated tablets}

Drug release was measured in a USP dissolution bath using apparatus II (Erweka DT 700, Husenstamn, Germany). The

Table I. Summary of HPLC parameters for DFS assay

\begin{tabular}{ll}
\hline \hline Parameter & \multicolumn{1}{c}{ Specification } \\
\hline Column & $250 \mathrm{~mm} \times 4.6 \mathrm{~mm}, 5.0 \mu \mathrm{m}$ Hypersil ${ }^{\circledR} \mathrm{BDS}$ \\
Flow rate & $1.0 \mathrm{~mL} /$ minute \\
Injection volume & $20 \mu \mathrm{L}$ \\
Wavelength & $254 \mathrm{~nm}$ \\
& $\mathrm{pH} 2.5 \pm 0.2$ phosphate buffer : methanol \\
Mobile phase & $(70: 30)$. \\
\hline
\end{tabular}


Table II. Post compression tests results

\begin{tabular}{|c|c|c|c|c|}
\hline $\begin{array}{c}\text { Physical appearance } \\
\text { (white color and round shape) }\end{array}$ & $\begin{array}{l}\text { Average weight } \\
\text { (mg) }\end{array}$ & $\begin{array}{l}\text { Average hardness } \\
\left(\mathrm{kg} / \mathrm{cm}^{2}\right)\end{array}$ & $\begin{array}{l}\text { Friability } \\
\quad(\%)\end{array}$ & $\begin{array}{c}\text { Average } \\
\text { disintegration time } \\
\text { (minutes) }\end{array}$ \\
\hline Compliant & $271.2 \pm .4$ & $8.6 \pm 1.2$ & 0.13 & $\begin{array}{l}\text { Not more than } 10 \text { minutes } \\
\text { in water }\end{array}$ \\
\hline
\end{tabular}

dissolution test for enteric coated tablets was performed as mentioned in the USP (USP 2007) adopting method B. In this method two different $\mathrm{pH}$ values were used at two different time stages. In the first stage $(\mathrm{pH} 1.2)$; the tablets were placed in $900 \mathrm{~mL}$ of $0.1 \mathrm{~N}$ hydrochloric acid in the USP dissolution bath and maintained at a temperature of $37 \pm 0.5^{\circ} \mathrm{C}$. The paddle stirring rate was set at $50 \mathrm{rpm}$. Six tablets were introduced into the apparatus and the apparatus was run for $2 \mathrm{~h}$. After the above outlined operation, an aliquot of the fluid was drawn and tested for content of DFS released. The specification for the acid phase is not more than $10 \%$ DFS dissolved. The acid was then drained from the vessel, and replaced with $\mathrm{pH} 6.8$ phosphate buffer. This last buffer was prepared by mixing $0.1 \mathrm{M}$ hydrochloric acid with $0.20 \mathrm{M}$ tribasic sodium phosphate $(3: 1)$. Sample aliquots were withdrawn from this buffer phase at different periods of time, and analyzed for the amount of DFS dissolved. The specification for the buffer phase is not less than $80 \%$ drug dissolved after 90 minutes. The samples were assayed by HPLC method at $254 \mathrm{~nm}$ wavelength (USP 2007).

\section{Stability study of enteric coated tablets}

Three batches of DFS enteric coated tablets were prepared and blister packed in aluminum-PVC foil. Samples from these three batches were then subjected for stability study according to ICH guidelines (ICH 2003). Tests were conducted at room temperature (RT) and accelerated stability conditions. Samples designed for RT storage were kept at $25 \pm 2^{\circ} \mathrm{C}$ and $65 \pm 5 \%$ relative humidity $(\mathrm{RH})$. These samples were tested at time 0,3 , $6,9,12,18$ and 24 months. The samples in the accelerated stability study were kept at $40 \pm 2^{\circ} \mathrm{C}$ and $75 \pm 5 \% \mathrm{RH}$ in humidity chamber (Binder GMBH Bergster, Tullingen, Germany) and tested at 0,3 and 6 month periods. Samples were tested for their appearance, disintegration, dissolution, hardness and DFS concentration using the previously mentioned procedures to evaluate the stability of the coated tablets.

\section{Results}

The purpose of this study is to develop and asses the behavior of DFS tablets enteric coated with AquaPolish E in the absence of a sub-coating layer. Enteric coating was success- fully done using AquaPolish E white coating aqueous dispersion. In order to achieve good coating results, uncoated tablets should have good parameters to withstand the coating process. The obtained dry and appropriately lubricated granules had good flowability resulting in low tablet weight variation. The granules were compressed without any problem and the prepared tablets were free from defects such as capping and lamination. Tablets of good mechanical strength (good breaking force higher than $7.0 \mathrm{Kps}$ ) and low friability (a maximum loss of mass less than 1\%) were obtained. Physical appearance, hardness, friability, weight variation and drug content evaluation of the uncoated tablets were found to be satisfactory under pharmacopeial standards of tablet evaluation (Table II). In fact, tablets used in enteric coating process must be sufficiently hard to support mechanical stresses and should show a very low potential for powder loss and edge chipping. Any defect in the uncoated tablet may result in localized weakness of the obtained enteric film coat.

Tablets were coated without having any visual defect such as roughness, orange peel appearance, chipping, tacking or other unacceptable flaws. Although traditional aqueous functional coating formulations may require many component mixing steps before starting the coating process, this new formulation was dispersed in the minimum amount of time, and produced acceptable weight gains. The coated tablets had no obvious defects or signs of peeling or chipping. Tablets were found to be robust and the obtained hardness remained constant within the stability period of the study (Table III and IV). The efficiency of the obtained enteric coat was determined by subjecting the coated tablets to gastric $\mathrm{pH}$, and drug release was analyzed using HPLC system. In fact, the disintegration test of enteric coated tablets was satisfactory since DFS tablets enteric coated with AquaPolish E showed complete acid resistance for $2 \mathrm{~h}$ but they were completely disintegrated within 10 minutes when they placed in buffered solution at pH6.8. In vitro drug release studies were carried out since these are considered the best tool for assessing in vivo drug behavior. A passing result for the in-gastric (acid) portion of the test is $\leq 10 \%$ dissolved. A passing result for the intestinal (buffer) portion of the test is $\geq 75 \%$ dissolved. The DFS release met the criteria outlined in this study i.e. less than $10 \%$ dissolved after 120 minutes in 
Table III Percentage of assay and average of drug release from enteric coated DFS (50 mg/tablet) in $0.1 \mathrm{~N} \mathrm{HCl}$ and pH 6.8 phosphate buffer (stored at room temperature for 24 months)

\begin{tabular}{cccccc}
\hline \hline $\begin{array}{c}\text { Period } \\
\text { (months) }\end{array}$ & $\begin{array}{c}\text { Physical appearance } \\
\text { (white color and round shape) }\end{array}$ & Hardness & $\begin{array}{c}\text { \% of DFS in acidic stage } \\
(\mathrm{pH} 1.2)\end{array}$ & $\begin{array}{c}\text { \% of DFS in alkaline stage } \\
\text { (pH 6.8 phosphate buffer) }\end{array}$ & \begin{tabular}{c} 
\% assay \\
\hline 0
\end{tabular} \\
\hline Compliant & $9.5 \pm 2.3$ & 0.7 & $96.5 \pm 2.3$ & $101.9 \pm 1.3$ \\
3 & Compliant & $8.1 \pm 0.2$ & 0.8 & $96.7 \pm 4.4$ & $100.5 \pm 1.1$ \\
6 & Compliant & $7.8 \pm 0.7$ & 0.3 & $96.3 \pm 0.8$ & $101.2 \pm 1.1$ \\
9 & Compliant & $9.4 \pm 1.3$ & 0.9 & $94.6 \pm 0.3$ & $100.6 \pm 1.1$ \\
12 & Compliant & $9.7 \pm 1.2$ & 0.7 & $97.1 \pm 3.8$ & $101.9 \pm 0.2$ \\
18 & Compliant & $9.8 \pm 2.0$ & 0.3 & $95.3 \pm 1.8$ & $100.8 \pm 1.7$ \\
24 & Compliant & $9.0 \pm 2.2$ & 0.4 & $96.7 \pm 2.1$ & $101.3 \pm 1.3$ \\
\hline
\end{tabular}

Table IV. Percentage of assay and average of drug release from enteric coated DFS (50 mg/tablet) in $0.1 \mathrm{~N} \mathrm{HCl}$ and pH 6.8 phosphate buffer $\left(40 \pm 2^{\circ} \mathrm{C}\right.$ and $75 \pm 5 \%$ RH for 6 months)

\begin{tabular}{|c|c|c|c|c|c|}
\hline $\begin{array}{l}\text { Period } \\
\text { (months) }\end{array}$ & $\begin{array}{c}\text { Physical appearance } \\
\text { (white color and round shape) }\end{array}$ & Hardness & $\begin{array}{c}\% \text { of DFS in acidic stage } \\
(\mathrm{pH} 1.2)\end{array}$ & $\begin{array}{l}\text { \% of DFS in alkaline stage } \\
\text { (pH } 6.8 \text { phosphate buffer) }\end{array}$ & $\%$ assay \\
\hline 0 & Compliant & $9.5 \pm 2.3$ & 0.7 & $97.5 \pm 2.3$ & $101.9 \pm 1.3$ \\
\hline 3 & Compliant & $8.5 \pm 1$ & 0.95 & $96.5 \pm 2.1$ & $100.2 \pm 1.7$ \\
\hline 6 & Compliant & $8.3 \pm 1.5$ & 1.3 & $95.5 .1 \pm 3.4$ & $99.3 \pm 1.5$ \\
\hline
\end{tabular}

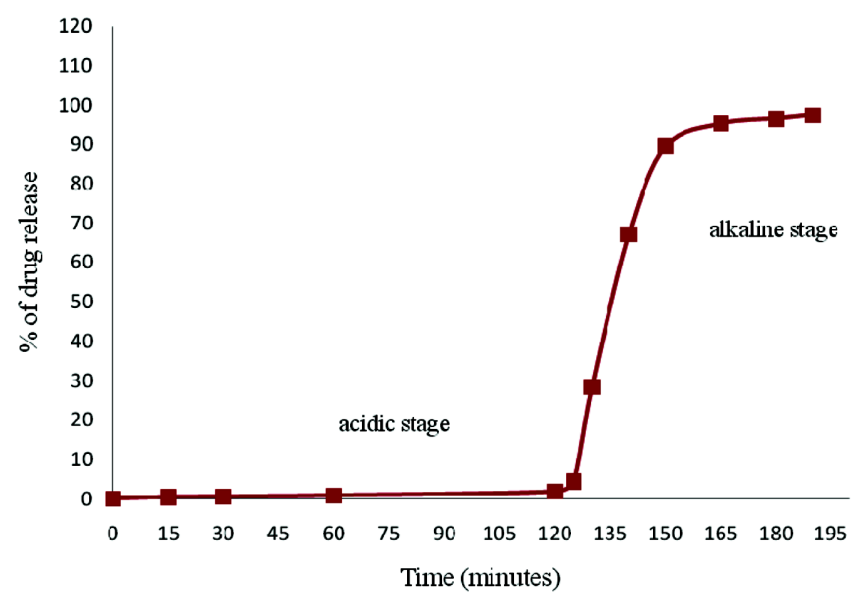

Figure 1. Dissolution profile of enteric coated DMS (50 mg/tablet) in $0.1 \mathrm{~N} \mathrm{HCl}$ and $\mathrm{pH} 6.8$ phosphate buffer.

acidic conditions and higher than $80 \%$ dissolved after 45 minutes in buffer solution at pH 6.8 as shown in Figure 1.

Results of both room temperature (RT) and accelerated stability conditions were satisfactory, showing no significant variation in physical characteristics, color, hardness or disintegration time of the coated tablets. Percent dissolution and assay were within the acceptable limits of USP as shown in Table III and IV.

\section{Discusion}

AquaPolish E dispersions is a completely formulated polymer system. This formulation contain selected materials that make its suitable for enteric coating. It contains pigments that help to prevent motting which result from uneven distribution of color in the coating, a problem related to water soluble days. The preparation of the aqueous dispersion consists of a simple addition of the powder formulations and propylene glycol to water. This requires little effort and time. The obtained dispersion was sieved to avoid the presence of any clumps that could result in gun blockages or alteration of the smoothness of the enteric coat. The dispersion was continuously stirred during the period of the coating process to avoid sedimentation and coalescence of particles. Tablet coating was carried out in conventional coating pan using spray coating technique. During coating, certain parameters such as temperature of coating pan and spray rate of coating dispersion were kept under great care in order to obtain the desired smoothness and uniformity of film coat. In fact, some process parameters of potential importance, including the temperature of coating pan and the spray rate of the coating dispersion were investigated by other researchers (Sauer et al, 2007; Parikh et al., 1993; Krogars et. $\mathrm{Al}, 2000)$. According to these studies, the temperature of the coating pan has no effect on the smoothness of the obtained coat when a low spray rate was used. Conversely, smoother films were obtained at higher spray rates and higher temperatures. In another study, pan speed and coating duration were also identified as variables significantly affecting content uniformity (Rege et al, 2003). It was shown that lower rates of drug release from the coated tablets may be obtained by using high inlet-air temperature and low spray rate of the polymeric 
dispersion during coating. Increased temperature for various time periods to remove water and solvent from the product affects the properties of final products (Frisbee et al., 2003). Sometimes, a subcoating step may be used to strengthen friable cores before the application of the functional coat or it may also be necessary to prevent interaction between the drug substance and the coating formulation ingredients. However, it is not desirable in terms of process time, complexity, cost and environmental pollution due to the use of organic solvents. In the present study, subcoating was avoided since the obtained core tablets were sufficiently robust and they did not require further strengthening by the use of subcoat. The obtained coated tablets were stable, indicating high compatibility between DFS and the used AquaPolish E. All data indicated that the film coat was essentially unchanged and provided the desirable enteric protection. Three batches of coated DFS were prepared and the previously mentioned parameters were tested under the same conditions. The results obtained from the three batches showed no significant differences for each set of these batches, indicating that this manufacturing process is reliable and reproducible.

\section{Conclusion}

A delayed release DFS (50 mg/tablet) was developed using AquaPolish E system without using a subcoating layer. Aqueous enteric coating was successfully conducted under lab-scale facilities. AquaPolish E system provides acceptable enteric performance in terms of appearance characteristics, stability and in vitro drug availability. The analytical testing results for all tested tablets, including both those stored at room temperature and those stored under accelerated stability conditions were within the specified criteria for passing results. Therefore, these findings suggest that aqueous enteric coating with AquaPolish E system is an easy and economical approach for preparing stable DFS delayed release tablets. Thus, the interaction between the alkaline DFS and the acidic groups of acrylic polymer present in Aquapolish $\mathrm{E}$ is minimum and does not affect the quality and stability of the coated tablets.

\section{Transparency declaration}

Neither author has any conflict of interest relevant to the content of this article.

\section{References}

Aulton, M.E., 2007. Coating of tablets \& multiparticulates. Pharmaceutics: the science of dosage form design, $3^{\text {rd }}$ ed., Churchill Livingston Elsevier, New York, 500-514.

Baudoux, M., Dechesne J.P., Delattre L., 1990. Film coating with enteric polymers from aqueous dispersions. Pharm Technol Int. 18-26.

Bushra, R., Shoaib, M.H., Aslam, N., Mehmood, Z., Durriya, H., 2010. Enteric coating of ibuprofen tablets (200 mg) using an aqueous dispersion system. Braz. J. Pharm. Sci. 99-107.

Derle, D.V., Gujar, K.N., Sagar, B.S.H., 2006. Adverse effects associated with the use of nonsteroidal anti-inflammatory drugs: An overview. Indian J Pharm Sci. 409-414.

Durriya, H., Shoaib, M.H., Mehmood, Z.A., Bushra, R., Yousuf, R. I., 2008. Development of Enteric Coated Flurbiprofen Tablets using Opadry/acryl-eze System. AAPS PharmSciTech. 9, 116121.

Frisbee, S.E., Mehta, K.A., Mcginity, J.W., 2002. Processing factors that influence the in vitro and in vivo performance of filmcoated drug delivery systems. Drug Deliv. 2, 72-76.

ICH Guidelines, 2003. Step 4 version, dated 6 February. Stability testing of new drug substances and products, Q1A(R2). Available at: http://www.ich.org/cache/compo/363-272-1. html\#Q1C

Krogars, K., Heinämäki, J., Vesalahti, J., Marvola, M., Osmo, A., Yliruusi, J., 2000. Extrusion-spheronization of $\mathrm{pH}$-sensitive polymeric matrix pellets for possible colonic drug delivery. Int J Pharm. 199, 187-194.

Parikh, N.H., Porter, S.C., Rohera, B.D., 1993. Aqueous ethylcellulose dispersion of ethylcellulose I. Evaluation of coating process variables. Pharm Res. 10, 525-534.

Porter, S.C., 2006. Coating of pharmaceutical dosage forms, Remington The Science and Practice of Pharmacy $21^{\text {th }}$ ed., Lippincott Williams \& Wilkins, New York, 929-933.

Rege, P.R., Garmise, RJ., L.H., 2003. Block, Spray-dried chitinosans: Part II: in vitro drug release from tablets made from spray-dried chitinosans. Int J Pharm. 252, 53-59.

Sauer, D., Zheng, W., Coots, L.B., McGinity, JW., 2007. Influence of processing parameters and formulation factors on the drug release from tablets powder-coated with Eudragit ${ }^{\mathbb{R}}$ L 100-55. Eur J Pharm Biopharm. 67, 464-475.

US Pharmacopeia XXX, 2007. US Pharmacopeial Convention, Rockville, MD, 1923-1927.

Wheatley, T.A., Steuernagel, C.R., 1997. Latex emulsion for controlled drug delivery. In: McGinity JW, editor. Aqueous Polymeric Coatings for Pharmaceutical Dosage Forms. 2nd ed. Marcel Dekker Inc, New York, 11-13.

http://www.webmd.com/drugs/mono-4049-Diclofenac+Sodium+EntericCoated + Tablet ++ Oral.asp 2 drugid $=4284 \&$ drugname $=$ Diclofenac + Sodium+Oral.

www.biogrund.com/ 